\title{
Las obras hidráulicas romanas en Tiermes. Organización espacial del territorio y asimilación de la intervención humana en el paisaje
}

\section{The Roman Hydraulic Structures in Tiermes. Landscape Settlement and Landmarks of Human Intervention}

\author{
Alfonso García de la Vega*
}

\section{INTRODUCCIÓN}

La pervivencia secular del asentamiento humano en el entorno de Tiermes confirma el interés de las sucesivas culturas por este ámbito geográfico, mostrando una referencia constante a un recurso natural, el agua. En este sentido, se mantiene un estrecho vínculo entre el manto freático de la paramera calcárea de la Sierra de Pela y los aprovechamientos hidrológicos humanos. De este modo, los rasgos naturales de este paisaje han cambiado a lo largo de los siglos por las intervenciones humanas.

De hecho, los manantiales han constituido un referente geográfico en la evolución cultural de este paisaje. Precisamente, esto podría explicar la presencia humana desde el Paleolítico en este sector nororiental del Sistema Central. Estos asentamientos se consolidaron en el desarrollo de las culturas celtíberas mediante las actividades relacionadas con la agricultura y la ganadería. En este sector geográfico, dichas actividades alcanzaron su esplendor en época romana, mostrando un leve declive con la aparición de la cultura visigoda y un relativo estancamiento que se mantuvo durante la Edad Media.

\footnotetext{
*Dpto. de Didácticas Específicas, Universidad Autónoma de Madrid. España (alfonso.delavega@uam.es).
} 
La cultura romana desarrolló sus conocimientos de ingeniería civil para extraer los recursos naturales que le proporcionaba el paisaje. Hay restos del roquedo empleado en sus construcciones, muestras de polen que apuntan al uso de determinadas especies vegetales y, entre otros recursos, el agua. En este sentido, los escasos vestigios del acueducto romano en Tiermes son la mejor evidencia constructiva de las obras hidráulicas acometidas en el entorno del macizo kárstico de la Sierra de Pela (figura 1).

En suma, en este trabajo se ofrece una interpretación geográfica sobre la dinámica natural de la Sierra de Pela, así como sobre la evolución de los asentamientos humanos. En este sentido, dicha interpretación se atiene al análisis de los registros de los depósitos tobáceos, a los análisis de polen y a las fuentes documentales. Se plantea así el estrecho vínculo existente entre los aprovechamientos hidrológicos y los asentamientos humanos, como consecuencia del funcionamiento del geosistema kárstico. De esta forma, la localización de los recursos naturales proporciona algunas claves para interpretar la ocupación del espacio y la evolución del paisaje.

\section{Geosistema kárstico de la Sierra de Pela. Características geográficas}

El concepto de geosistema kárstico es un término geográfico acuñado por Vaudour (1986a:2), quien lo define como el «sistema hidrológico que consta de al menos una unidad de drenaje en rocas calcáreas permeables y solubles. Ello incluye un impluvium, una unidad de almacenamiento subterránea, uno o varios puntos de emergencia localizados sobre el piedemonte [...] según las morfoestructuras regionales y la posición respectiva de los niveles de base geomorfológica y kárstica».

Este mismo autor destaca el grado de intervención humana sobre las unidades de paisaje kárstico, diferenciando tres tipos de geosistemas: natural, antrópico y antropizado. También señala la existencia de sistemas menores en interacción a diferente escala espacio-temporal, que se caracterizan por su estructura, funcionamiento e historia. Por tanto, el geosistema estrecha el vínculo entre el hombre y el medio natural (Vaudour, 1986b).

En Tiermes, las obras hidráulicas constituyen un elemento destacado en la aportación romana a ese paisaje cultural y se mimetizan en él. Dicha intervención de ingeniería se relaciona con el geosistema de la Sierra de Pela, localizado a unos pocos kilómetros del yacimiento romano. Siguiendo la tipología de Vaudour, los elementos culturales de este paisaje definen un geosistema antrópico, pues las construcciones civiles se mimetizan, otorgando una identidad propia como ocurre en sectores geográficos del Mediterráneo. 
El desarrollo del modelado kárstico de este geosistema de la Sierra de Pela viene condicionado principalmente por la morfoestructura sinclinal. A su vez, en esta unidad morfoestructural dominan dos tipos de factores: litotectónicos e hidrográficos.

\section{Pautado litotectónico en el relieve kárstico de la Sierra de Pela}

La paramera de la Sierra de Pela corresponde a un sinclinal delimitado por dos fallas, la de Somolinos al Norte y la de Cabras al Oeste. De hecho, la falla de Somolinos delimita los dos ámbitos litológicos del geosistema, además de constituir el escarpe de línea de falla de la Sierra. Estos dos sectores son: uno oriental, dominado por el afloramiento de calizas y dolomías jurásicas sobre los materiales triásicos y otro occidental, definido por los sedimentos cretácicos sobre los materiales triásicos (García de la Vega, 2008a).

FIGURA 1

ENTRE CUEVAS DE AYLLÓN Y RETORTILLO DE SORIA SE EXTIENDEN LAS LLANURAS Y CRESTAS DE LA COMBE DE TIERMES (MITAD SUPERIOR DEL MAPA).ENTRE GRADO DEL PICO E HIJES, LA PARAMERA CALCÁREA DE LA SIERRA DE PELA; DE OESTE A ESTE SE DESTACA EL ESCARPE SEPTENTRIONAL DE LA SIERRA

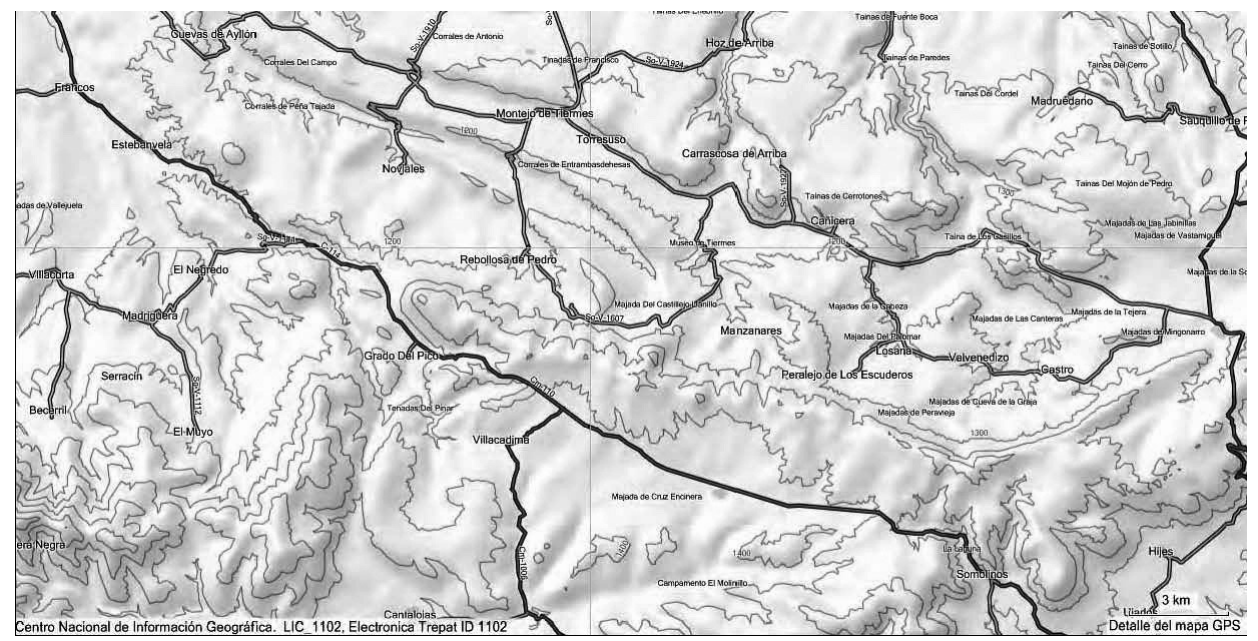

Fuente: Cartografía: CNIG, 2009 
Los factores litotectónicos se refieren a la litología calcáreo-dolomítica y al entramado tectónico del geosistema kárstico. En este sentido, tan importantes son las grandes líneas tectónicas que compartimentan la unidad, tales como la conjunción de las pequeñas fallas y, sobre todo, de las diaclasas, como los materiales calcáreos característicos en el desarrollo del modelado kárstico de la Sierra.

El borde septentrional del macizo kárstico de la paramera presenta un escarpe de línea de falla que determina la denominada Sierra de Pela, desde el Pico de Grado hasta Retortillo de Soria (García de la Vega, 2008b) (figura 2). Este escarpe está definido por las fallas de Somolinos y Retortillo, que separan esta unidad de relieve de la combe de Tiermes (García de la Vega, 2001). El límite meridional coincide con la llanura que domina la depresión de los Condemios, desde Cantalojas hasta Miedes de Atienza. El margen occidental concuerda parcialmente con la falla de Cabras y con el contacto entre el zócalo de las sierras de Ocejón y Riaza y la cobertera mesozoica de la paramera. El margen oriental parece más difuso, pues no existe una separación neta entre esta sierra y la de Bulejo, que, convencionalmente, hemos situado en el Torreplazo.

\section{Rasgos hidrográficos de un geosistema kárstico mediterráneo: Sierra de Pela}

En este sentido, conviene resaltar el desarrollo endokárstico del macizo calcáreo, como muestran los caudalosos manantiales permanentes. Precisamente, la estructura sinclinal y la consiguiente estratificación subhorizontal, junto al diaclasado y fracturación del roquedo calcáreo, condicionan un permanente manto freático. Esto contrasta con la escasa presencia de cavidades, salvo la Sima y algunas dolinas menores, y la presencia de las tobas.

En el geosistema de la Sierra de Pela, como interfluvio de las cuencas del Duero y Tajo, se abren tres hocinos fluviokársticos: los ríos Bornova, Sorbe y Aguisejo. Todos ellos cuentan con un entramado de afluentes y barrancos ahocinados de lecho rocoso y seco y de fondo plano, propios del modelado kárstico (figura 3).

Estos tres ríos poseen su correspondiente manadero de elevado caudal, que además constituye su propio nacimiento. Los manaderos de Aguisejo, Pedro y Rebollosa de Pedro desaguan en el Duero, mientras que hacia la cuenca del Tajo tan sólo es significativo el Manadero del Bornova, tributario del Henares. También existen algunas fuentes permanentes e intermitentes que nutren el caudal de los principales ríos. 


\section{FIGURAS 2 Y 3}

ARRIBA, EL ESCARPE DE LA SIERRA DE PELA, VISTA DESDE LAS CRESTAS DE ARENISCAS DE LA COMBE DE TIERMES. ABAJO, PERSPECTIVA AÉREA

DEL INTERFLUVIO DE LA SIERRA DE PELA, DIVISORIA ENTRE LAS CUENCAS DEL DUERO, AL FONDO Y AL NORTE, Y DEL TAJO, CON EL RÍO BORNOVA EN PRIMER PLANO Y HACIA EL SUR
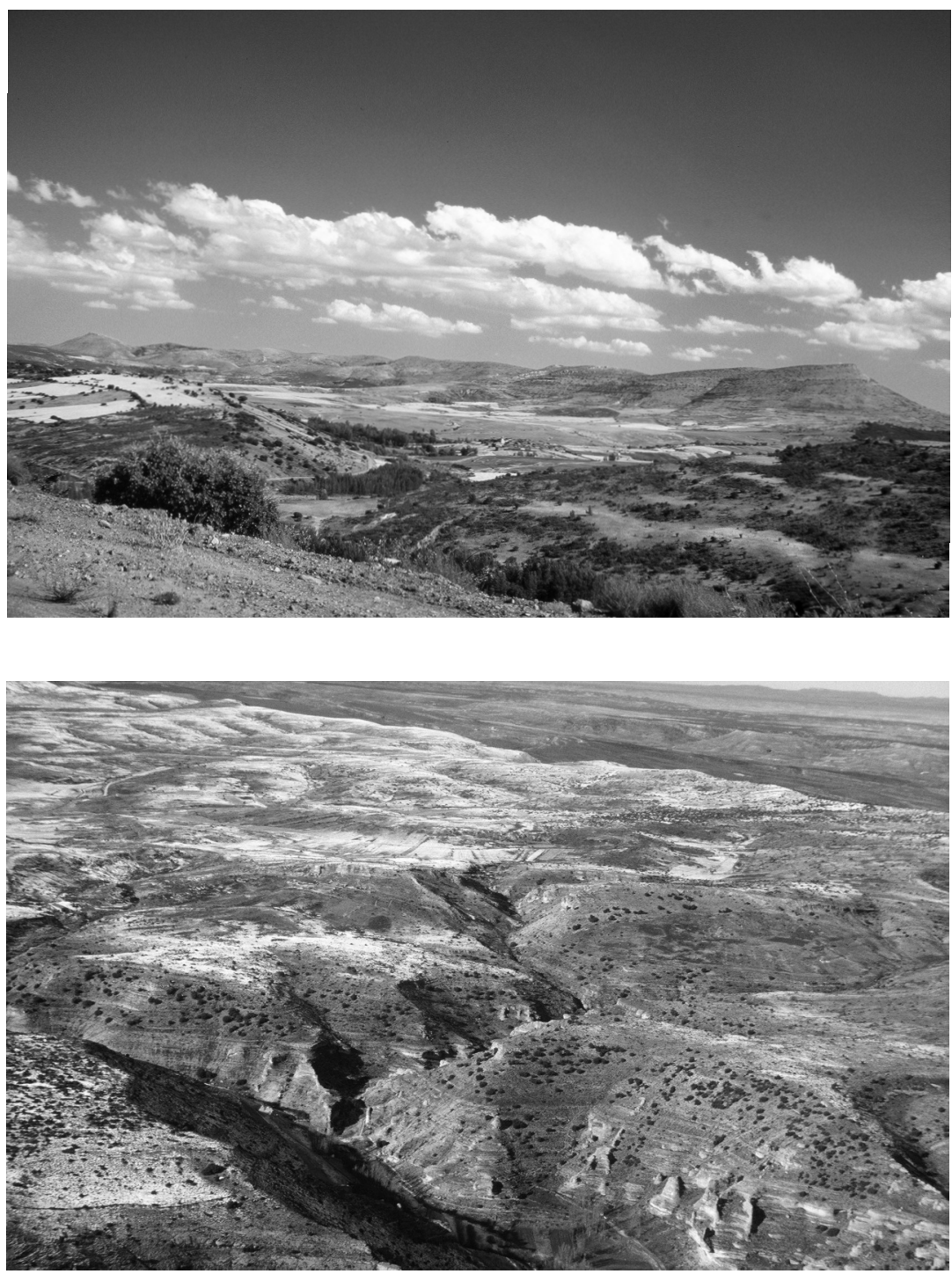

Estudios Geográficos, Vol. LXXII, 271, pp. 437-459, julio-diciembre 2011 ISSN: 0014-1496, eISSN: 1988-8546, doi: 10.3989/estgeogr.201117 


\section{Rasgos morfoclimáticos de la paramera calcárea de la Sierra de Pela}

Durante el Cuaternario, la evolución paleoclimática ha generado diversos rasgos morfológicos en este geosistema. Si los sucesivos procesos de incisión lineal han definido el entramado fluvial, los edificios tobáceos constituyen el depósito constructivo de dicha evolución y, sobre todo, suponen el registro de numerosos datos geográficos. En este sentido, los análisis de los depósitos tobáceos y otros análisis de materiales bióticos muestran datos concluyentes sobre la aparición de determinadas fases cálidas y húmedas durante el tránsito del Pleistoceno superior al Holoceno.

En el interior de la paramera y situadas en la cabecera del río Bornova, se localizan una terraza aluvial y una toba de barrera que, al cerrar el valle, han formado la Laguna de Somolinos. La acumulación de tipo terraza travertínica que recubre el fondo del alto valle del Bornova se localiza en el horcajo del propio río con el barranco del Recuenco. Su extensión contrasta con su escaso espesor, menos de dos metros, recortada por el trazado del río. Por otro lado, en el valle del río Bornova, la toba de barrera represa la Laguna de Somolinos, cuyo espesor alcanza los diez metros. Ordoñez, González y García del Cura (1986) cartografiaron esta toba como perteneciente al Holoceno-Actual.

En la vertiente septentrional, en el escarpe de falla de la Sierra de Pela, se localizan dos manantiales permanentes, como lo son Pedro y Rebollosa de Pedro, y otros temporales de menor caudal. Las tobas de estas dos fuentes son de surgencia, como refleja la estructura sedimentaria del depósito. Los dos edificios se localizan ligeramente exentos del farallón calcáreo que forma la Sierra. Estas tobas permiten señalar la ubicación del antiguo exutorio de ambas fuentes, situado entre los 1.260 y 1.280 metros de altitud, respectivamente.

Por consiguiente, podemos afirmar que, en principio, la localización y la altitud permiten ofrecer una relación directa entre el Manadero de Pedro, como fuente emisora, y las obras hidráulicas llevadas a cabo en época romana en Tiermes, dado que el manantial de Rebollosa de Pedro se haya más alejado de Tiermes y alcanza menor altitud.

\section{Los registros geoarqueológicos y paleoclimáticos en la evolución del paisaje}

Pentecost (1995) y Ford y Pedley (1996) han examinado la localización y las fases genéticas de las tobas y los travertinos en todos los ámbitos geográficos. Las fases constructivas de las tobas del dominio mediterráneo aparecen registradas a 
lo largo del Cuaternario. En España, en el alto Tajo, los estudios realizados muestran dos o tres etapas climáticas con un aumento de humedad durante el Cuaternario (González Amuchástegui y González Martín, 1989). Ordóñez, González y García del Cura (1986) confirman dos generaciones de travertinos en el valle alto del Tajuña, donde la altitud y las acumulaciones crioclásticas permiten distinguir dos episodios, uno del Cuaternario reciente y otro del Holoceno.

En cuanto a las dataciones absolutas, en el clásico estudio de valle del Henares, Gladfelter (1970) realizó algunos análisis con $\mathrm{C}_{14}$ y estableció dos episodios de construcción. La primera fase correspondía al período comprendido entre los $19.450 \pm 350$ años B.P. y $12.520 \pm 190$ años B.P., mientras que la segunda fase coincide en unas muestras datadas en el intervalo situado entre los $6.560 \pm 130$ años B.P. y $4.020 \pm 110$ años B.P.

En el área de estudio, de los análisis de datación absoluta mediante la técnica de la termoluminiscencia que se realizaron sobre las muestras tomadas de los edificios tobáceos, se concluye que la formación de estos depósitos carbonatados tuvo lugar en el transcurso de dos fases: una en el Pleistoceno superior y otra correspondiente al tránsito del Pleistoceno-Holoceno (García de la Vega, 2010a). En otros sectores de la Península Ibérica, la aportación de los análisis de datación absoluta mediante los isótopos U/Th, realizados sobre los travertinos en Tabernas (Almería) registra dos períodos climáticos óptimos (Delgado Castilla, 2009), similares a las dos fases mencionadas.

En el entorno de Tiermes se han hallado restos de estos depósitos sedimentarios, vinculados a los manantiales del acuífero de la Sierra de Pela. Desde el Pleistoceno superior, la formación de estos edificios tobáceos sugiere, como hipótesis, diferentes fases relacionadas con climas más templados y húmedos. En este sentido, el diagrama sobre las fases climáticas durante el Pleistoceno superior de Renault-Miskovsky (1986) refleja dos máximos de clima templado hacia los 22-18 ka B.P. y 16-14 ka B.P. Por consiguiente, la configuración paisajística de este sector geográfico coincide con períodos de tiempo atemperado en la fase fría dominante.

Por tanto, los registros realizados y el consiguiente análisis de diferentes depósitos carbonatados han confirmado que la toba constituye un testimonio de los cambios climáticos acaecidos desde el Pleistoceno medio en el Mediterráneo (Magnin et al., 1990). Por su parte, Nicod (1986) destacó la intervención antrópica sobre las condiciones paleoclimáticas generadoras del edificio travertínico en el transcurso del Holoceno-Actual. La actividad humana modifica sus características naturales y provoca determinados desequilibrios ecológicos. En este mismo sentido, González-Sampériz et al. (2009) destacan la incidencia climática en la definición y la dinámica de los asentamientos hu- 
manos. Por el contrario, Mayewski et al. (2004) reconocen las variaciones climáticas mundiales durante el Holoceno, al margen de la actividad humana.

\section{AsENTAMIENTOS HUMANOS EN EL ENTORNO DE TIERMES}

La pervivencia secular del asentamiento humano en el entorno de Tiermes confirma el interés por los recursos naturales de este enclave geográfico. Casi se podría asegurar que las culturas celtíbera, romana y visigoda fueron refinando los usos y aprovechamientos del sector nororiental del Sistema Central. Braudel (1953) resaltó la preferencia de la cultura romana por poblar las llanuras en el dominio montañoso de los paisajes mediterráneos. Sin embargo, Tiermes se localiza en un prominente roquedal de areniscas, desde donde se dominan las llanuras fértiles de la combe.

\section{Algunos hallazgos previos a la romanización}

Afirmaba Terán Álvarez (1966, p. 71) que «una civilización se define como un repertorio de ideas y creencias, instituciones, usos, normas de conducta social, técnicas de trabajo material. Todo un complejo de creaciones espirituales y materiales, que tiene su reflejo en la manera como los grupos sociales hacen su instalación en el medio, lo interrogan e indagan sus posibilidades y lo organizan en consecuencia».

En este mismo sentido, los hallazgos de restos arqueológicos en abrigos y simas del entorno de este sector, tanto en la vertiente meridional y septentrional del Sistema Central como en la cuenca del Duero, proporcionan información sobre los primeros poblamientos. Los emplazamientos celtíbero y romano de los últimos milenios atestiguan que los grupos humanos escogieron asentamientos próximos a los geosistemas kársticos mediterráneos a lo largo del Cuaternario. Los recursos naturales, el agua de las fuentes junto a los abrigos naturales del roquedo calcáreo, constituyeron suficiente reclamo.

Estas tobas determinan la presencia de manantiales, que configuraron un paisaje donde la presencia humana empezaba a registrar sus primeras manifestaciones culturales. Así, en este sector, los primeros registros corresponden a las pinturas rupestres localizadas en la gruta del Portalón (Ortego Frías, 1963; Balbín Behrmann y Bueno Ramírez, 1990 y Gómez Barrera, 1993). Esta cavidad se localiza en el alto de la paramera de la Sierra de Pela, una ubicación que pudiera estar motivada por las surgencias del borde y cumbre de la citada 
sierra. Más aún si añadimos las pinturas rupestres esquemáticas descubiertas en el sector de la Sierra de Ocejón, no muy lejano de la Sierra de Pela (Sebastián Caudet y Gómez-Barrera, 2003).

Asimismo, se han registrado restos de industria y arte mueble en Estebanvela, en el extremo occidental de la combe de Tiermes, cuyos análisis en diferentes niveles estratigráficos de datación absoluta con $\mathrm{C}_{14}$ indican un intervalo comprendido entre los $15.500 \pm 50$ años B.P. y los $11.000 \pm 50$ años B.P. (Cacho Quesada et al. 2003). En un trabajo de síntesis, Balbín Behrmann y Alcolea González (1994) ofrecían una edad entre 18.000 años B.P. y 15.000 años B.P. para el arte paleolítico localizado en diversas cuevas de la meseta castellana. Según los mismos autores, corresponde al tránsito del final de la cultura Solutrense y el comienzo de Magdaleniense.

Las manifestaciones morfológicas procedentes de la dinámica del relieve exokárstico, es decir, los depósitos tobáceos del macizo calcáreo, son indicadores de los recursos hídricos existentes en estos paisajes. Dichos indicios, contrastados con los hábitos de los pueblos, decidirían la ubicación del asentamiento humano, como atestiguan la dedicación agraria o ganadera de los distintos pueblos celtíberos de la submeseta septentrional.

\section{El abandono de las construcciones termestinas y consecuencias paisajísticas}

Se desconocen fuentes bibliográficas y documentales sobre el abandono de Tiermes, aunque éste debió acontecer con la decadencia del Imperio. La cultura visigoda muestra un cierto interés en Pedro, donde se construye una ermita que data del siglo vi. En esa época, tampoco existen evidencias sobre el mantenimiento del acueducto. Esto quiere decir que, pese a los registros y pozos de decantación localizados en el trazado del canal de distribución de Tiermes, el desuso de las obras hidráulicas romanas comenzó a ser patente. Ahora bien, además del abandono, hemos hallado algunos indicios geomorfológicos del escaso uso que, por razones desconocidas, debieron tener las obras de ingeniería realizadas en Tiermes. A consecuencia de dicho abandono se desencadenó el proceso de meteorización en el canal (figura 4).

Hasta el momento, en el área de estudio, no se han registrado depósitos sedimentarios que pudieran ofrecer datos precisos sobre las condiciones climáticas durante la época romana. No obstante, en otros sectores peninsulares se distinguen cuatro fases climáticas durante dicha época (Martín-Puertas et al., 2009). Todas ellas pertenecen a un período definido por la humedad, aunque 
ARRIBA, DETALLE DEL CANAL NORTE LABRADO EN LAS ARENISCAS JUNTO A

LA PUERTA OESTE DE TIERMES. ABAJO, DETALLE DEL CANAL NORTE Y, AL FONDO, EL BORDEGA (1.544 M), PICO DEL ESCARPE DE LA SIERRA DE PELA
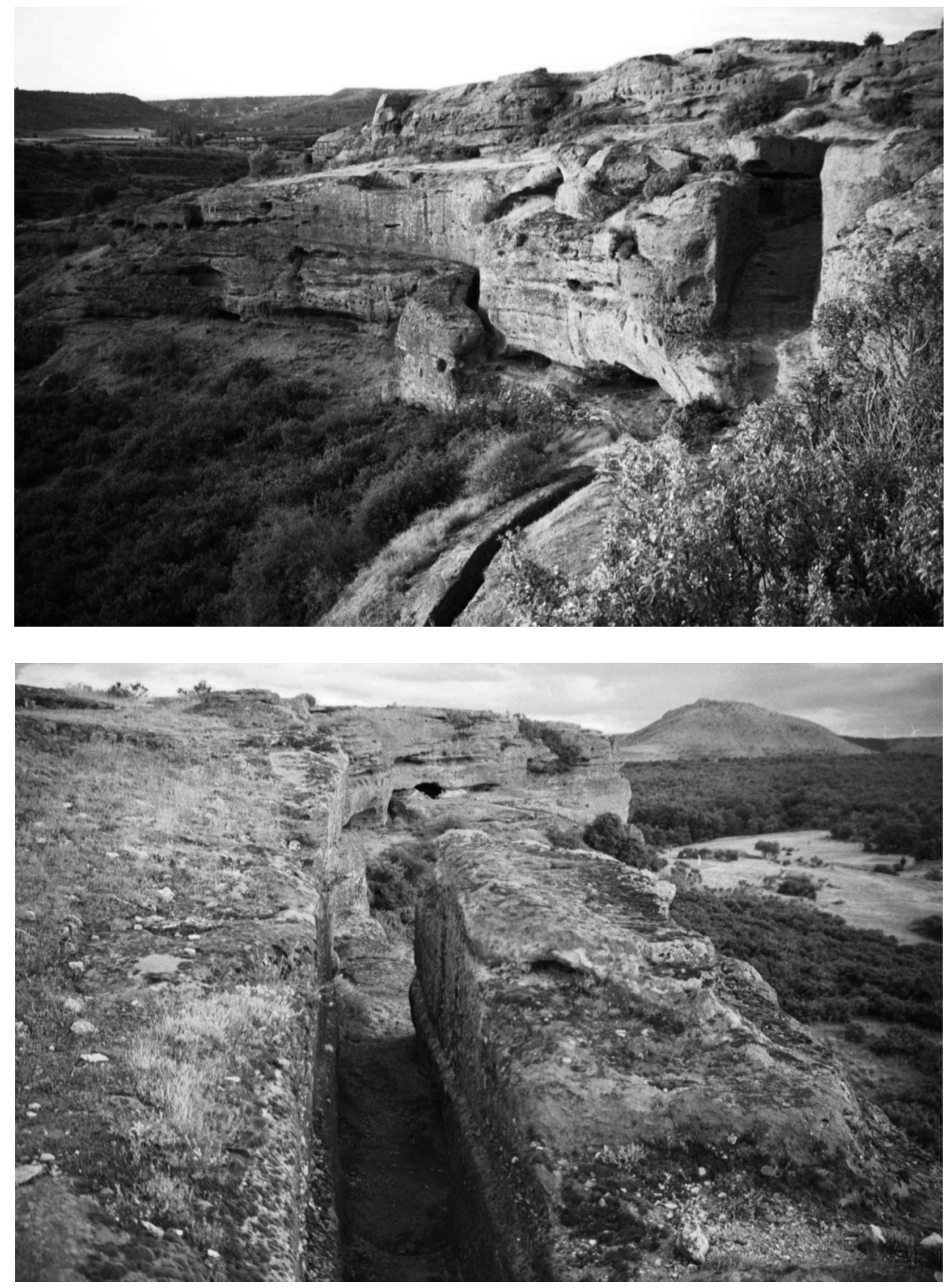

Estudios Geográficos, Vol. LXXII, 271, pp. 437-459, julio-diciembre 2011 ISSN: 0014-1496, eISSN: 1988-8546, doi: 10.3989/estgeogr.201117 
la tercera fase, que corresponde cronológicamente a la presencia romana, muestra un incremento de los índices de aridez como consecuencia, según los mismos autores, del impacto de la actividad humana en el medio. Estas conclusiones son válidas para otras áreas lacustres estudiadas en la Península Ibérica y en Europa, donde se exhibe un dominio del mencionado período de humedad durante la expansión del Imperio Romano.

Franco Múgica et al. (2001), mediante el análisis de los registros polínicos, revelan la escasa presencia del pinar con un correlativo aumento de las partículas de carbón durante la época romana. Por consiguiente, estos datos refuerzan la conclusión de una intensa actividad de los romanos sobre los recursos naturales del entorno para consolidar las obras hidráulicas, que se mantiene durante el último milenio. La regresión del pinar, como consecuencia de la actividad humana, contrasta con la tendencia a repoblar de forma natural el piso montano en el tránsito del Pleistoceno al Holoceno (Franco Múgica et al., 2000).

Los ingenieros romanos reconocían la ubicación de los mantos freáticos en los macizos calcáreos de los páramos, como se comprueba en las numerosas localidades situadas junto a manantiales en el ámbito mediterráneo: Nîmes (Francia), Haidra y Dougga (Túnez), Phaeselis y Termessos (Turquía), según recogió en un trabajo anterior (García de la Vega, 2010b).

Una de las principales obras de ingeniería en Tiermes durante la época romana fue el acueducto, las canalizaciones y demás construcciones hidráulicas que constituyeran la infraestructura de captación de aguas de los manantiales de la Sierra de Pela. Las condiciones del Manadero de Pedro apuntan a que fuera el manantial elegido por los romanos: una distancia lineal de 3,6 km (Martínez Caballero, 2008); un caudal permanente de 7 1/s (Hernando del Cura, 2001) y una altitud de $1.280 \mathrm{~m}$ (figura 5).

Hernando del Cura (2001) ha propuesto un itinerario para el acueducto, que enlazara el manadero de Pedro con Tiermes, siguiendo el perímetro del Cerro de la Mata hasta llegar a Sotillo de Caracena. Desde allí, el trazado discurriría suavemente rectilíneo ajustado al farallón de la cresta de areniscas hasta alcanzar la Peña Grande. Allí se registran las huellas del canal extraurbano cincelado que se une a los canales de distribución de Tiermes, un enlace que debiera situarse junto a la Puerta del Oeste (Argente Oliver y Díaz Díaz, 1995).

Hernando del Cura (2001) tuvo en consideración los factores clásicos en la construcción de los acueductos para establecer el posible trazado del acueducto. Sin embargo, Fernández Casado (1972) subrayó la preferencia romana por la fábrica subterránea frente a vuelo. Por tanto, nos podríamos decantar por el itinerario cuyo trazado discurre orientado a levante, junto al escarpe de 
la Sierra de Pela, que al llegar a Sotillo de Caracena tomaría dirección septentrional, labrada bajo el melojar que recubre la cresta de areniscas hasta alcanzar la Peña Grande. En todo este recorrido, el acueducto podría permanecer subterráneo o semienterrado, labrado sobre las mismas areniscas triásicas donde se asienta Tiermes, una hipótesis alternativa a la supuesta dificultad de realizar la misma obra en la litofacies de bloques de cuarcita que afloran en el Cerro de la Mata, correspondiente al recorrido alternativo.

Tal vez, el acueducto se situara a pie del escarpe de la Sierra de Pela hasta llegar a Sotillo, pues allí existen suficientes restos de las crestas areniscas meridionales de la combe de Tiermes que pudiera utilizarse para realizar el conducto labrado (García de la Vega, 2001). Este trazado también mantendría el grado de caída por gravedad para llevar el agua hasta Tiermes. Ahora bien, no se ha apreciado resto alguno de fábrica del acueducto en el mencionado escarpe de la Sierra, tampoco en la cresta de areniscas ni en el Cerro de la Mata, aunque aún podrían permanecer ocultos (figura 6).

\section{FIGURA 6}

A LA IZQUIERDA ABAJO, EL ESCARPE DE LA SIERRA DE PELA Y LOS DOS PRINCIPALES MANANTIALES DE REBOLLOSA DE PEDRO, AL OESTE, Y DE PEDRO AL SUR. A LA DERECHA ARRIBA, LAS RUINAS DE TIERMES. ENTRE LA FUENTE DE PEDRO (1.280 M) Y TIERMES (1.220 M) SE LOCALIZA EL CERRO DE LA MATA (1.339 M)

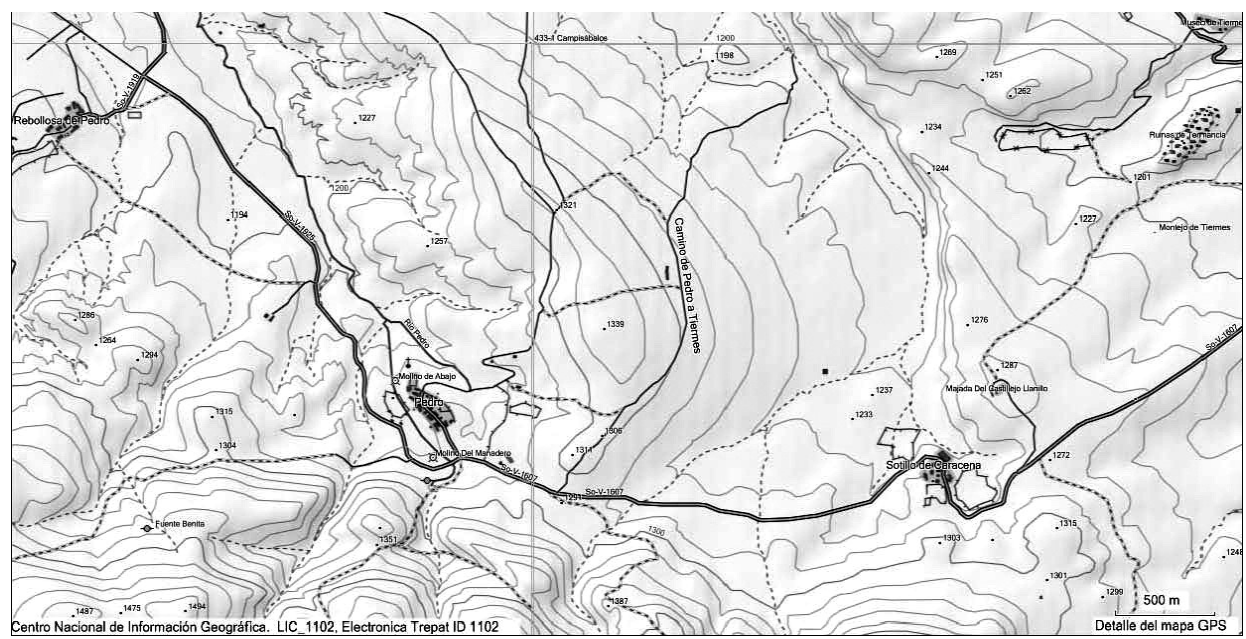

Fuente: Cartografía: CNIG, 2009

Estudios Geográficos, Vol. LXXII, 271, pp. 437-459, julio-diciembre 2011 ISSN: 0014-1496, eISSN: 1988-8546, doi: 10.3989/estgeogr.201117 
Las primeras observaciones del canal termestino labrado en las areniscas ofrecen evidentes muestras relacionadas con los procesos de meteorización. Esto es, la erosión del viento y la lluvia, principalmente, habría ocasionado numerosos taffoni en el nivel de base de la canalización del Norte. Además, la proximidad de la canalización a las escarpadas crestas de areniscas habría facilitado la apertura de diaclasas latentes que, con el paso del tiempo, se han abierto, generando una caída de bloques por gravedad en dichos escarpes.

Además, los cantiles de rodeno revelan un roquedo de material muy fino en sedimentación cruzada que, en sectores puntuales, se interrumpe por lechos de cantos de cuarcita de tamaño heterogéneo. Esta observación se descubre en el canal meridional, cuestión que debió repercutir en la factura de la obra hidráulica.

En el entorno próximo a la ciudad de Tiermes, en la vía romana labrada sobre las areniscas para salvar el farallón de la cresta rocosa, se hallan los procesos de caída de bloques como consecuencia de esta apertura de diaclasas. Por tanto, parece ser que durante los primeros siglos de la Edad Media el canal meridional estuviera mucho más completo que como se presenta en la actualidad su sector exterior, debido a la reducida caída de bloques del cantil.

Todo ello se deduce como consecuencia de las observaciones realizadas en la obra hidráulica de irrigación construida en Tiermes. De manera que la meteorización y el diaclasado latente proporcionaron una resistencia al uso y mantenimiento, pese a los pozos de decantación de las canalizaciones termestinas.

Una segunda base de interpretación sobre el abandono de las construcciones hidráulicas termestinas se refiere al escaso espesor de la costra calcárea de los canales. En ciudades de manantiales procedentes de macizos calcáreos y donde el uso del acueducto se ha mantenido en el tiempo, las paredes del canal del mismo muestran una gruesa capa de concreción calcárea, como en el caso más representativo de Nîmes (Guendon y Vaudour, 1986 y Gilly, 1986). En Tiermes, la concreción calcárea generada como consecuencia de la presencia de las aguas carbonatadas del manantial de Pedro es inferior a un milímetro de espesor en las canalizaciones septentrional y meridional, sin evidentes muestras de la construcción del acueducto.

E incluso podemos afirmar que, una vez abandonado este enclave geográfico, el acueducto cayó en desuso y se descuidó el necesario mantenimiento de la limpieza de los canales labrados en la ciudad rupestre de Tiermes y de las construcciones elaboradas en las afueras de la misma. Debido a las causas mencionadas, el acueducto debió de desmoronarse y las construcciones y sus materiales debieron de cambiar de uso con el paso de los siglos. Una prueba 
FIGURAS 7 Y 8

ARRIBA, LA VÍA ROMANA LABRADA EN LA CRESTA DE ARENISCAS DE LA COMBE, CUYO FARALLÓN TIENE QUE SALVAR. ABAJO, EL MENCIONADO ABRUPTO ROCOSO DE ARENISCAS Y, AL FONDO, EL BORDEGA
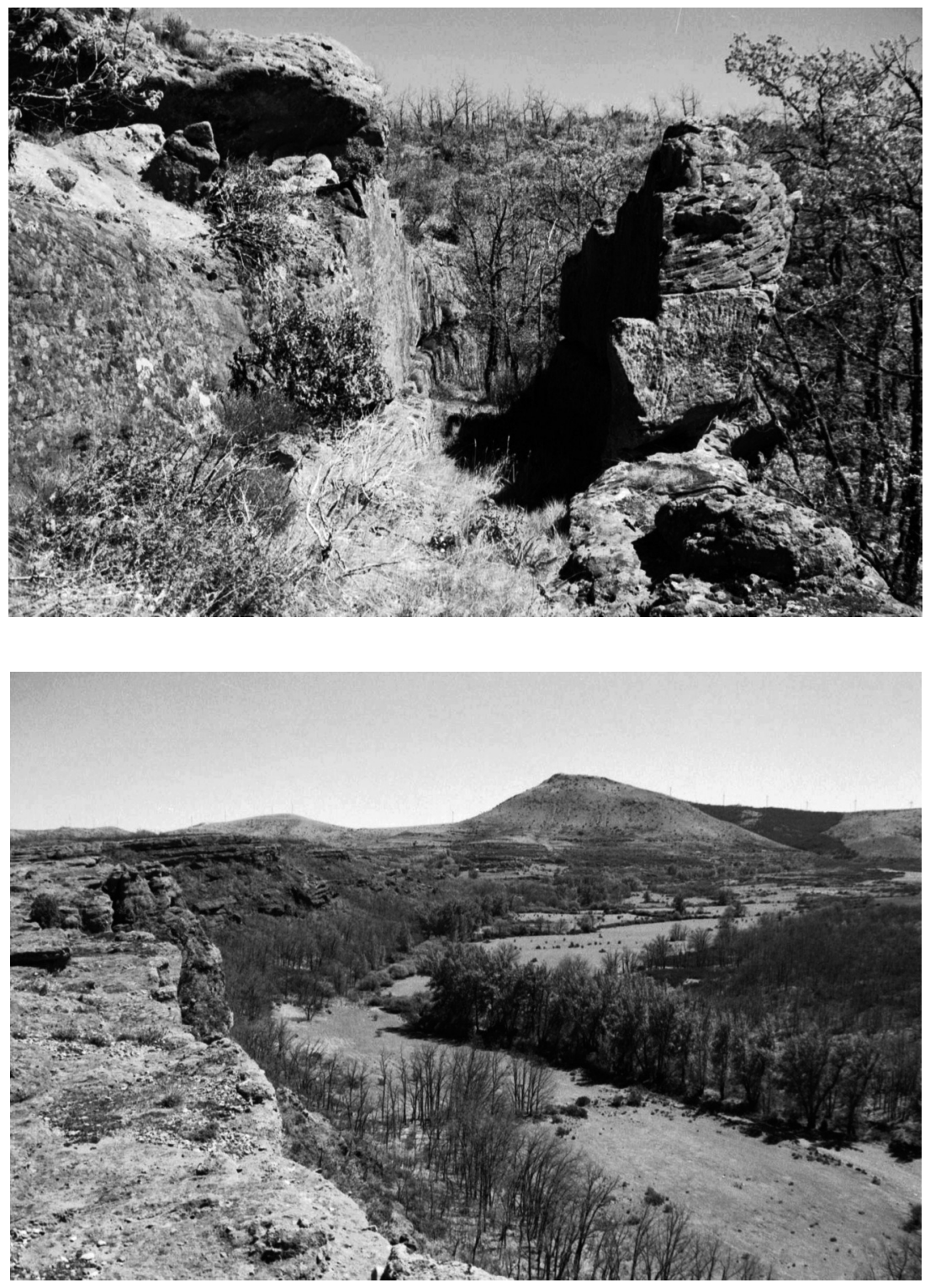

Estudios Geográficos, Vol. LXXII, 271, pp. 437-459, julio-diciembre 2011 ISSN: 0014-1496, eISSN: 1988-8546, doi: 10.3989/estgeogr.201117 
de este deterioro es la escasez de restos del acueducto, pues tan sólo quedan algunos sillares dentro de la ciudad y en el entorno más próximo al yacimiento arqueológico. Por consiguiente, todo ello apunta a que la construcción del acueducto desde el manantial de Pedro a Tiermes apenas se aprovechó durante la etapa de desarrollo de la cultura romana en la ciudad.

\section{Las transformaciones del paisaje durante la época romana}

Seguramente, tras la cultura romana, Tiermes dejó de constituir un referente estratégico para las sucesivas culturas que lo poblaron. En consecuencia, tanto las construcciones de ingeniería civil como la organización social establecida por la cultura romana fueron abandonadas. Tan sólo existen restos, y la presencia visigoda apenas está representada. Sin embargo, la decadencia durante la época medieval de este sector se debe, sobre todo, a la frontera localizada en la margen izquierda del río Duero y a los enclaves defensivos, localizados mucho más alejados de Tiermes.

Así, Sáenz Ridruejo (1984) menciona los hitos que delimitaban las provincias de Soria y Guadalajara, haciendo referencia a una de las fuentes más antiguas, la de Loperráez (1788). Así, se sugieren numerosos topónimos que registran voces romances con una referencia explícita a una «torre de vigilancia». Entre ellos están, Pico de Grado, Bordega, Torreplazo, Torrevicente, Toril de Mata, Torre de Marraduel y Torrejón, situado al nordeste de Atienza.

A escasos kilómetros al norte de Tiermes se hallan algunas construcciones defensivas medievales como las torres de Liceras y Montejo de Tiermes. E incluso algunos castillos como los de Caracena, al norte, y Galve de Sorbe, al sur, constituyen pasos exclusivos de valles y portillos entre las cuencas del Duero y Tajo.

La toponimia alude a figuras de la épica medieval descritas por Dozy (1877), como el general árabe Galib, que ha quedado en el pico Bordega (Burt Galib, esto es, Puerto de Galib), según interpreta Sáenz Ridruejo (1984), incluso en Galve de Sorbe también existen referencias al personaje. O bien, el Cid, que ha quedado de manifiesto en el barranco del Borbocid. De hecho, un camino supera la sierra, bordeando el mencionado pico y descendiendo por el citado barranco. Un camino convertido en posible alternativa al puerto de Somosierra y un viario discreto hasta los baluartes estratégicos de Atienza (García de la Vega, 2004).

Además, Sáenz Ridruejo (1984) revisa la campaña de Almanzor en el sector de Tarancueña, localidad muy próxima a Tiermes, y describe el despo- 
blado existente entre el Duero y la Cordillera Central. Cita «en los bosques de encina y roble de Liceras, Montejo, Torrevicente, Tarancueña...», pero no hace mención a Tiermes. Ello supone una interesante aportación sobre un área despoblada desde la Baja Edad Media. Seguramente, las obras hidráulicas romanas ya habrían desaparecido obliteradas bajo un manto de sedimentos. Así, el interés que pudiera despertar este sector en aquel momento atañe a la ubicación estratégica y al viario. De hecho, las calzadas romanas sí fueron utilizadas durante la Edad Media, aunque no se tiene constancia de trabajos para su mantenimiento (figuras 7 y 8 ).

Este sector estudiado corresponde a una frontera medieval, donde el flujo de personas a uno y otro lado de la misma originó determinadas actividades, tal como se refleja en la factura de las ventanas de estilo mudéjar en el ábside de la iglesia de Santa Coloma de Albendiego. Sin embargo, se carece de referencias documentales sobre los asentamientos humanos en el área de Tiermes, de manera que en las referencias literarias medievales se describen estos parajes como lugar de tránsito.

En este sentido, en el Cantar del Mío Cid se encuentran los siguientes versos (2691-99):

«A ssiniestro dexan Atiença, una penna muy fort, la sierra de Miedes passáronla estos, por los Montes Claros aguijan a espolón; assiniestro dexan a Griza que Alamos pobló, allí son caños de a Elpha encerró;

a diestro dexan a San Estevan, mas cade aluon.

Entrados son los ifantes al Robredo de Corpes, los montes son altos las ramas pujan con las nuoves, elas bestias fieras que andan aderredor»

El Cantar hace referencia al tortuoso paso, localizado en el extremo oriental de la paramera de Sierra de Pela, junto a Torreplazo, entre los poblamientos de Miedes de Atienza y Retortillo de Soria. Martín de Riquer (1977) realza la trama narrativa en romance castellano del Cantar y destaca el verismo geográfico del poema frente a la epopeya clásica o medieval francesa. Asimismo, García Pérez (1993) ha considerado que estos versos hacen una referencia simbólica a la galería abierta por los romanos en Tiermes, esto es, a la canalización subterránea meridional. Este autor interpreta que Alamós, deidad identificada con Hércules, encerró a Elfa en los caños romanos, refiriéndose a la mencionada canalización. Además, las alusiones a los animales destacan la riqueza cinegética descritas en el Libro de Montería. 
Todo ello pudiera significar que, según se apuntaba más arriba, en época medieval, el despoblado supuso la regeneración arbórea y, probablemente, de la fauna, a causa de la repoblación natural. Sin embargo, parece que el escarpado cantil meridional de Tiermes, donde se localiza el canal subterráneo, habría podido reconocerse desde lejos. Así, con el sol de poniente, las escarpadas crestas de rodeno meridional de la combe de Tiermes debieron llamar la atención por su color y, más aún, por la canalización.

\section{CONSIDERACIONES FINALES}

En un geosistema kárstico el agua se convierte en el recurso natural principal. Más aún en este caso, por cuanto este macizo kárstico constituye el interfluvio y el paso alternativo natural a Somosierra. La dinámica natural del geosistema kárstico de Pela generó la construcción de los edificios tobáceos en el interior de sus valles y en el escarpe de la Sierra. El funcionamiento del manto freático proporciona caudal a los manantiales permanentes, mientras que los temporales brotan cuando el nivel del acuífero se sitúa al máximo. Si bien la apariencia del geosistema no ofrece suficientes datos sobre el caudal de sus fuentes. De hecho, en este karst dominan las formas exokársticas sobre las endokársticas.

En este sector nororiental del Sistema Central, los primeros pobladores se distribuyeron por los abrigos que les proporcionaba el relieve de crestas de areniscas de la combe de Tiermes y por las cavidades y simas del modelado kárstico de la paramera de la Sierra de Pela. Se han registrado dos fases climáticas, mediante datación absoluta, una situada en el Pleistoceno superior y la segunda en el tránsito del Pleistoceno al Holoceno. Estas dos fases pudieran corresponder a fases climáticas templadas y húmedas, unas etapas que pudieron coincidir con el desarrollo álgido de los asentamientos y de la actividad humana, como corroboran los restos arqueológicos correspondientes al Paleolítico.

Del mismo modo que estos primitivos grupos humanos encontraron condiciones para establecerse en este sector geográfico, las sucesivas culturas, celtíbera y romana, debieron considerar óptimos los recursos naturales que proporcionaba este paisaje. Así, debido a la propia dinámica del karst, los edificios tobáceos y los manantiales proporcionaron un atractivo para el emplazamiento de la población. Ahora bien, el conocimiento de los diferentes paisajes mediterráneos proporcionaba a los romanos un criterio selectivo mayor para la ubicación del poblamiento. 
No obstante, con independencia de los recursos naturales, este asentamiento pudo responder a varios planteamientos. El primero de ellos se refiere a reforzar los emplazamientos interfluviales de las cuencas peninsulares. Así, junto a Clunia y Numancia, se refuerza la encrucijada de las cuencas del Duero y el Tajo y, ligeramente alejada, la cuenca del Ebro. El segundo planteamiento supone la transformación del poblamiento celtíbero de Tiermes en Termancia, aprovechando el fértil valle de la combe, donde quedó confinado el pueblo vencido. En este planteamiento se destaca el aumento de las construcciones civiles, incluyendo la construcción del acueducto y canalizaciones en el interior de la ciudad. Asimismo, se realizaron los dos principales enlaces del viario, en dirección meridional, y otro hacia la actual Segovia, con el fin de establecer los enlaces con todos los asentamientos de la Hispania romana.

La caída del Imperio supondría el abandono de las estructuras de la organización social en todas las ciudades romanas, hasta el extremo que, según prueban las referencias documentales medievales, este sector se convirtió en un despoblado. La ciudad de Tiermes quedó mimetizada con el entorno, fracturadas las obras romanas a cincel, generando una caída de bloques en los cantiles. En unas ocasiones, las diaclasas se abrían y los bloques debieron caer en gravedad; en otras ocasiones, como consecuencia de la aparición de fases de mayor frío, se producían situaciones de hielo y deshielo que generarían procesos de gravedad. Todo ello provocaría el desmoronamiento de las escarpadas vertientes de la ciudad, colapsando el funcionamiento de irrigación en el interior de la ciudad y el enlace con la fuente de Pedro.

Por otra parte, resulta muy difícil establecer un trazado del acueducto sin haber hallado vestigio alguno del mismo. Sin embargo, las primeras observaciones de las canalizaciones muestran una manifiesta meteorización de la arenisca y una concreción carbonatada en el canal labrado, como sucede en otros lugares del Mediterráneo. Todo ello nos conduce a pensar que el aprovechamiento del acueducto debió desarrollarse durante los siglos del asentamiento romano y que con el paulatino abandono de la población las obras romanas perdieran su función, dando lugar a otras interpretaciones de los habitantes. Así, el acueducto, al caer en desuso, terminaría por desmoronarse completamente y los selectos sillares romanos de las canteras próximas de calizas y areniscas se habrían utilizado para los perfiles de las viviendas. Asimismo, las canalizaciones hidráulicas del interior de la ciudad, al perder su función original, junto al deterioro debido a los procesos de meteorización, terminaron por convertirse en otro tipo de construcciones domésticas (almacenes y silos) o defensivas (trinchera). 


\section{AgradeCIMIENTOS}

Agradezco la ayuda concedida al proyecto EH-2008-013-00 del CEHOPU, a las sugerentes aportaciones para mejorar el artículo de los revisores anónimos y a Esther Andrés Caballo, también por la traducción de los resúmenes al inglés y francés.

Recibido: 09/03/2010

Aceptado: 08/02/2011

\section{BIBLIOGRAFÍA}

Argente Oliver, J. L. y Díaz Díaz, A. (1995): Tiermes, Guía del Yacimiento y Museo. Valladolid, Junta de Castilla y León.

Balbín Behrmann, R. y Bueno Ramírez, P. (1990): “Arte rupestre levantino en Guadalajara”. Revista de Arqueología, 106, pp. 16-24.

Balbín Behrmann, R. y Alcolea González, J. J. (1994): “Arte paleolítico de la meseta española". Complutum, 5, pp. 97-138.

Braudel, F. (1953): El Mediterráneo y el mundo mediterráneo en la época de Felipe II. México D.F., Fondo de Cultura Económica, 2 vols. (1. edición original, 1949).

Cacho Quesada, C. et al. (2003): "El registro arqueológico del Pleistoceno superior final en el abrigo de la Peña de Estebanvela (S. de la Cuenca del Duero, Segovia, España)", en G. Flor (ed.): Actas de la XI Reunión nacional de Cuaternario. Oviedo, AEQUA-Universidad de Oviedo, pp. 191-198.

Delgado Castilla, L. (2009): "Edades U/Th de los travertinos cuaternarios de la cuenca de Tabernas (Almería) y sus implicaciones en la evolución geodinámica y paleoambiental de ésta". Cuaternario y Geomorfología, 23 (1-2), pp. 65-76.

Dozy, R. (1877): Historia musulmana española hasta la conquista de Andalucía por los Almorávides, 711-1110, traducción por F. de Castro. Barcelona, Imprenta Salvador Aceña y Cía., 4 tomos.

Fernández Casado, C. (1972): Acueductos romanos en España. Madrid, Instituto Eduardo Torroja.

Ford, T. D. y Pedley, H. M. (1996): "A Review of Tufa and Travertine Deposits of the World". Earth-Science Reviews, 41, pp. 117-175.

Franco Múgica, F. et al. (2000): "El papel de los pinares en la vegetación holocena de la Península Ibérica". Ecología, 14, pp. 235-251.

Franco Múgica, F. et al. (2001): "Evolución de la vegetación en el sector septentrional del macizo de Ayllón (Sistema Central). Análisis polínico de la turbera de Pelagallinas", Anales del Jardín Botánico de Madrid, no 59 (1), pp. 113-124. 
García de la Vega, A. (2001): "Evolución morfoestructural de la combe de Tiermes", en F. Manero (coord.): Espacio natural y dinámicas territoriales. Valladolid, Sociedad Española de Geomorfología, pp. 83-94.

García de la Vega, A. (2004): "Los condicionamientos físicos de aquellos caminos vinculados con el arte románico de la Sierra de Pela (Guadalajara)", en M. Criado del Val (coord.): Actas del VI Congreso Internacional de Caminería Hispánica, Italia-España 2002. Madrid, Ministerio de Fomento-Cedex, vol. 1, pp. 143-158.

García de la Vega, A. (2008a): "El karst de la Sierra de Pela: un interfluvio como relieve invertido (Sistema Central)", en J. Benavente y F. J. Gracia (eds.): Trabajos de Geomorfología en España, 2006-2008. Cádiz, SEG, pp. 37-40.

García de la Vega, A. (2008b): "Contribución a la evolución geomorfológica del escarpe de falla del sector nororiental del Sistema Central (España)". IV Congresso Geomorfologia, Braga (Portugal), octubre 2008.

García de la Vega, A. (2010a): "Découvertes géoarchéologiques et datations absolues pour la reconstitution des paysages méditerranéens", en International Colloquium on Geoarchaeology: "Landscape Archaeology. Egypt and the Mediterranean World". El Cairo, septiembre 2010.

García de la Vega, A. (2010b): "Dynamique culturale dans l'évolution des paysages fluviaux méditerranéens", International Colloquium on Geoarchaeology: "Landscape Archaeology. Egypt and the Mediterranean World", El Cairo, septiembre 2010.

García de la Vega, A. y Alonso Otero, F. (1997): "El paisaje del sector oriental del Sistema Central y sus construcciones de piedra en seco", en La pedra en sec. Obra, paistge i patrimoni. IV Congrés Internacional de Construcció de Pedra en Sec, Mallorca, setembre 1994. Mallorca, Consell Insular de Mallorca-Leader, pp. 267-278.

García Pérez, G. (1993): "Elfa, la mujer-serpiente del Cantar del Mío Cid”. Ateneo, 1, pp. 87-96.

Gilly, J. C. (1986): "Étude géochimique des incrustations de l'aqueduc romain conduisant les eaux d'Uzes à Nîmes: détermination de l'origine des eaux d'alimentation". Méditerranée, 57 (1-2), pp. 131-139.

Gladfelter, B. (1970): Meseta and Campiña Landforms in Central Spain. Chicago, University of Chicago Press.

Gómez Barrera, J. A. (1993): "Las pinturas rupestres de Villacadima (Guadalajara)". Revista de Arqueología, 146, pp. 6-13.

González Amuchástegui, M. J. y González Martín, J. A. (1989): “Geomorfología de las formaciones tobáceas del valle del río Gallo en el área de Molina de Aragón”. Cuaternario y Geomorfología, 3 (1-4), pp. 63-72.

González-Sampériz, P. et al. (2009): "Patterns of human occupation during the early Holocene in the Central Ebro Basin (NE Spain) in response to the 8.2 ka climatic event". Quaternary Research, 71, pp. 121-132.

Guendon, J.-L. y Vaudour, J. (1986): "Les concrétionnements de l'aqueduc de Nîmes". Méditerranée, 57 (1-2), pp. 140-151. 
Hernando del Cura, M. (2001): "El abastecimiento de las aguas romano a Tiermes". I. T. 57, pp. 26-33.

Loperráez Corvalán, J. (1788): Descripción histórica del Obispado de Osma. Madrid, Imprenta Real, 3 tomos, (reimpr. 1988, Madrid, Turner).

Magnin, F. et al. (1990): "Travertine as evidence for environmental and climatic changes. A middle Pleistocene example in Mediterranean France", en Geochemistry of the Earth's surface and of mineral formation (2nd International Symposium), pp. 173-175.

Martín Puertas, C. et al. (2009): "The Iberian-Roman Humid Period (2600-1600 cal yr BP) in the Zoñar Lake varve record (Andalucía, southern Spain)". Quaternary Research, 71, pp. 108-120.

Martínez Caballero, S. (2008): "El agua en Tiermes”, en J. Mangas Manjarrés y S. Martínez Caballero (eds.): El agua y las ciudades romanas. Madrid, Ediciones 2007, pp. 257-314.

Mayewski, P. A. et al. (2004): "Holocene climate variability". Quaternary Research, 62, pp. 243-255.

Nicod, J. (1986): "Facteurs physico-chimiques de l'accumulation des formations travertineuses". Méditerranée, pp. 161-164.

Ordóñez, S.; González, J. A. y García del Cura, M. A. (1986): "Pétrographie et morphologie des édifices tuffeux quaternaires du centre de l'Espagne". Méditerranée, 57 (1-2), pp. 52-60.

Ortego Frías, T. (1963): "Las pinturas rupestres de El Portalón, en el término de Villacadima (Guadalajara)". Ampúrias, 25, pp. 61-104.

Pentecost, A. (1995): "The Quaternary Travertine Deposits of Europe and Asia Minor". Quaternary Science Reviews, 14, pp. 1005-1028.

Renault-Miskovsky, J. (1986): L'environnement au temps de la Préhistoire. Paris, Masson, 183 pp.

Riquer, M. de (1977): "Prólogo al Cantar del Cid", en R. Menéndez Pidal (ed.): Cantar del Cid. Madrid, Espasa-Calpe, pp. 9-34.

Sáenz Ridruejo, C. (1984): "Identificaciones toponímicas en la antigua Tierra de Atienza y sus confines", en F. Chueca, E. Lafuente, R. Lapesa y M. Terán (coords.): Homenaje a Julián Marías. Madrid, Espasa Calpe, pp. 657-668.

Sebastián Caudet, A. y Gómez-Barrera, J. A. (2003): "Las pinturas rupestres esquemáticas del Covacho del Ocejón I (Valverde de los Arroyos, Guadalajara)". Saldvie, 3, pp. 1-13.

Terán Álvarez, M. de (1966): "Una ética de conservación y protección de la naturaleza", en Homenaje a don Amando de Melón. Zaragoza, Instituto Juan Sebastián Elcano e Instituto de Estudios Pirenaicos (C.S.I.C.), pp. 69-76

Vaudour, J. (1986a:2): "Introduction à l'étude des géosystèmes karstiques". Travaux Unité Associée 903 (CNRS), 15, pp. 1-8.

Vaudour, J. (1986b): "Travertins holocènes et pression anthropique". Méditerranée, 57 (1-2), pp. 168-173. 


\title{
RESUMEN
}

Durante cuatro siglos, la ocupación romana ha dejado numerosos restos de las obras hidráulicas llevadas a cabo en Tiermes y su entorno. El manto freático de la paramera calcárea de la Sierra de Pela ha constituido un referente geográfico atractivo debido a sus manantiales. Entre ellos, el Manadero de Pedro representa el hito geográfico e hidrográfico en este sector nororiental del Sistema Central. Este paisaje ha ofrecido numerosas posibilidades para los primeros asentamientos de los grupos humanos dedicados a la agricultura y la ganadería, como atestiguan los restos geoarqueológicos hallados desde el Pleistoceno superior. El emplazamiento aislado de Tiermes, junto a la fertilidad de las tierras circundantes, condicionó el asentamiento de los celtíberos en un interfluvio de las cuencas del Duero y Tajo. Las construcciones y aprovechamientos de los recursos naturales llevadas a cabo por los romanos determinaron una estructura espacial y definieron la asimilación paisajística de las obras realizadas en dicho enclave estratégico.

Palabras Clave: Tiermes; Sierra de Pela; geosistema kárstico; obras hidráulicas romanas.

\begin{abstract}
After four centuries of Roman's occupation in Tiermes and its surroundings, numerous remnants of their hydraulic works are still found there. The aquifer inside the limestone plateau of Sierra de Pela has ever been considered an alluring geographical landmark because of its plentiful springs. Among them, Manadero de Pedro constitutes the most outstanding geographical and hydrographical milestone in the northeast area of the Sistema Central range. This landscape seems to have been looked promising for the first human settlers devoted to agriculture and cattle rising, as it is so proved by the geoarchaeological remains found since Late Pleistocene. The isolated site at Tiermes, and the neighbouring fertile lands, encouraged the Celtiberians to settle down around this area, which represents the watershed between Douro and Tagus basins. Both the buildings raised and the natural resources exploited by the Romans conditioned a unique spatial structure, with the construction site fully merged into the landscape on this strategic spot.
\end{abstract}

KEY WORDS: Tiermes; Sierra de Pela; Karstic Geosystem; Roman hydraulic works.

\section{RÉSUMÉ}

Depuis quatre siècles de l'occupation romaine à Tiermes et aux environs, autant de ruines des travaux hydrauliques y menés à bien en sont restées. La nappe phréatique du plateau calcaire de Sierra de Pela constitue un référent géographique attirant en raison de ses sources. Parmi celles-ci se trouve le Manadero de Pedro, celui qui représente le fait géographique et hydrographique les plus marquant dans ce secteur au nord-ouest du Sistema Central. Ce paysage avait beaucoup à offrir pour les premiers peuples s'y établissant, qui se consacraient à l'agriculture et à l'élevage, dont il fait 
preuve la grande quantité des restes géoarchéologiques découverts depuis le Pléistocène supérieur. L'emplacement isolé à Tiermes, aussi que la fertilité des sols environnants, a entraîné l'établissement du peuple celtibère dans l'interfluve des bassins des fleuves Douro et Tage. Les constructions et l'exploitation de ressources naturelles menées par les Romains ont déterminé une structure spatiale particulière et ont abouti au mimétisme dans le paysage des ouvrages bâtis dans ce site naturel stratégique.

Mots CLÉS: Tiermes; Sierra de Pela; géosystème karstique; ouvrage hydraulique romain. 